\title{
Correction to: Analysis of the Influence of the Thickness and the Hole Radius on the Calibration Coefficients in the Hole-Drilling Method for the Determination of Non-uniform Residual Stresses
}

\author{
J.M. Alegre ${ }^{1} \cdot$ A. Díaz ${ }^{1}$ (D) - I.I. Cuesta ${ }^{1} \cdot$ J.M. Manso $^{2}$
}

Published online: 1 May 2020

(C) Society for Experimental Mechanics 2019

Correction to: Experimental Mechanics (2019) 59:79-94

https://doi.org/10.1007/s11340-018-0433-0

Due to an error introduced during the production process, Fig. 11 appeared incorrectly in the original publication of this article. It appears correctly here.

Publisher's Note Springer Nature remains neutral with regard to jurisdictional claims in published maps and institutional affiliations.

The online version of the original article can be found at https://doi.org/ $10.1007 / \mathrm{s} 11340-018-0433-0$

\footnotetext{
A. Díaz

adportugal@ubu.es

1 Structural Integrity Group, Escuela Politécnica Superior, Universidad de Burgos, Av Cantabria s/n, 09006 Burgos, Spain

2 SUCONS Research Group, Escuela Politécnica Superior, Universidad de Burgos, C/Villadiego s/n, 09001 Burgos, Spain
} 


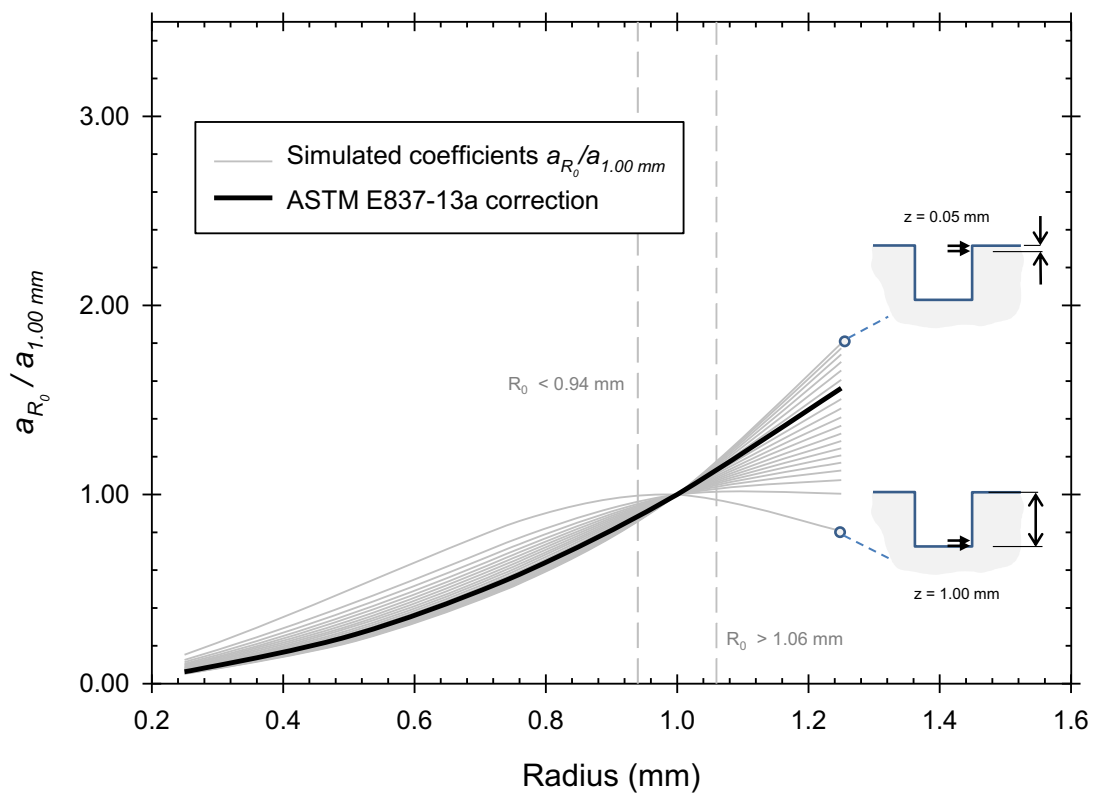

